\title{
Espinosa e a liberdade de ensinar
}

\author{
Fernando Bonadia de Oliveira *
}

Resumo: Este pequeno trabalho pretende interpretar o parágrafo 49 do oitavo capítulo do Tratado politico, de Espinosa (1632-1677), que versa sobre as academias fundadas às custas da República. Nesse curto parágrafo, constante de sete linhas, o filósofo holandês afirma que essas academias servem mais para constranger o espírito do que para cultivá-lo e que, ao contrário, em uma República livre, dar-se-á a cada um a licença para ensinar publicamente, às suas custas e com o perigo de sua reputação. Tal fragmento relaciona-se diretamente ao vigésimo capítulo do Tratado teológico-político, outra obra do mesmo filósofo, que aborda a liberdade de pensar e de dizer. Este trabalho, através de uma interpretação do parágrafo 49, evidenciará, finalmente, que a liberdade de ensinar, na república livre pensada por Espinosa, situa-se entre a organização do imperium e a iniciativa do professor.

Palavras-chave: Espinosa, Bento de (1632-1677); liberdade de ensinar; Tratado político; Filosofia da Educação.

\section{The freedom of teaching in Spinoza's work}

Abstract: This brief work is intended at interpreting the $49^{\text {th }}$ paragraph of the $8^{\text {th }}$ chapter of Spinoza's Political Treatise, about the academies founded by the Republic. In this short paragraph, with seven lines, the Dutch philosopher states that the academies supported by the Republic were useful rather to constrain one's spirit than to cultivate it. He also states that in a free Republic, on the other hand, each person should be given a license to teach publicly, at his/her own risk (in terms of reputation) and expense. Such passage is strictly related to the $20^{\text {th }}$ chapter of $A$ Theologico-Political Treatise, written by the same author, approaching freedom of thought and speech. Through an interpretation of the $49^{\text {th }}$ paragraph, this work will finally show that freedom of teaching, in a free republic as thought by Spinoza, is placed between the imperium organization and a teacher's initiative.

Key words: Espinoza, Bento de (1632-1677); freedom of teaching; Political Treatise; educational philosophy.

Mestre em História e Filosofia da Educação pela Faculdade de Educação da Unicamp, Campinas, SP, Brasil.fernandofilosofia@hotmail.com 


\section{Introdução'}

O parágrafo 49 do Capítulo 8 do Tratado político ${ }^{2}$, de Espinosa, que aborda a organização do estado aristocrático, é de extrema importância para a compreensão plena do significado da "liberdade de ensinar" de que esse mesmo filósofo faz elogio no Capítulo 20 de seu outro tratado, o Tratado teológico-político ${ }^{3}$. O parágrafo, em si, é extremamente curto, composto por sete linhas, segundo a edição de Carl Gebhardt, Spinoza opera, em que se encontra o texto na língua original.

Esse parágrafo recebeu, na tradição interpretativa de Espinosa, alguma consideração. Todavia, não se encontra ainda disponível uma análise pontual desse fragmento que interessa para a filosofia da educação moderna, na medida em que fornece subsídios teóricos para compreender o que esse filósofo entende por "liberdade de ensinar".

Este trabalho ocupar-se-á, a princípio, em mostrar a complexidade desse parágrafo. Para tanto, serão situados, primeiramente, o escopo e o lugar que ocupa o TP no conjunto da obra espinosana; depois, o objetivo e o lugar que ocupa o Capítulo 8 nessa obra e, finalmente, o contexto em que, nesse capítulo, aparece o parágrafo 49 , que será aqui interpretado. Posteriormente, apresentar-se-á seu conteúdo geral e determinadas leituras que dele foram feitas por alguns comentadores da obra espinosana. Em último lugar, será empreendida propriamente a interpretação pontual do fragmento e serão afirmadas suas relações com outros escritos de Espinosa, como a Ética, o Tratado teológicopolítico e as Epistolas.

\section{Contexto do parágrafo 49 do Capítulo 8 do Tratado político}

Não é simples estabelecer uma interpretação do parágrafo 49, que põe termo ao oitavo capítulo do $T P$, se se considerarem todas as questóes que o circunscrevem.

A primeira delas diz respeito, logo de início, ao lugar que ocupa o TP no conjunto das obras de Espinosa. Trata-se da última obra do filósofo, cuja redação se iniciou, provavelmente, no ano de 1675 e estendeu-se pelos últi-

I. As referências à obra de Espinosa serão dadas segundo o volume Spinoza opera, editado por Carl Gebhardt e dividido em quatro volumes. Portanto, no texto da referência, indicar-se-á a sigla "SO" para informar que se trata de Spinoza opera, o número do volume e o número da página, conforme o exemplo: SO3, p. 272. Será dada a conhecer ao leitor, ademais, a obra que está sendo citada, seu capítulo, parte ou parágrafo.

2. Doravante: TP.

3. Doravante: TTP. 
mos anos de vida de Espinosa, ficando inacabada pelo autor à altura do Capítulo $11^{4}$.

Segundo a própria divisão oferecida por Espinosa em uma carta a um amigo $^{5}$, o primeiro capítulo desse tratado comporta uma introdução; o segundo trata do direito natural; o terceiro, do direito dos poderes dos soberanos; o quarto, dos negócios dependentes do governo dos poderes soberanos; o quinto, do ideal extremo e soberano que pretende qualquer sociedade; o sexto e o sétimo capítulo, por sua vez, cuidam da organização do império ${ }^{6}$ monárquico, a fim de que este não termine em tirania; o oitavo, o nono e o décimo capítulo versam sobre a organização do império aristocrático; e, por fim, o incompleto décimo primeiro capítulo trata do império democrático.

Ocupado em tratar do império aristocrático, Espinosa afirma, no parágrafo 47 do oitavo capítulo, que estão apresentados os fundamentos principais da aristocracia, restando abordar apenas algumas questōes importantes que foram, a partir de então, acrescentadas pelo autor. A primeira delas refere-se à distinção de vestimenta entre os patrícios e os plebeus e ao modo como deve ser tratado, eventualmente, o caso de um patrício perder seus bens. No parágrafo 48, Espinosa aborda a distinção entre o perjúrio em nome de Deus e o perjúrio em nome da pátria; no parágrafo 49, enfim, consta a consideração espinosana sobre as academias fundadas às custas da República e, como já se sabe, esse é o parágrafo que, em particular, interessa a este estudo.

\section{O parágrafo 49: conteúdo e comentários}

Após os estudos que originaram este trabalho, optou-se por traduzir o parágrafo, aqui em questão, da seguinte maneira:

As academias, fundadas às custas da República, são instituídas menos para cultivar o espírito do que para o entravar. Todavia,

4. Nas Opera posthuma (OP), publicadas pelos amigos de Espinosa no ano de sua morte ( 1677 ), ao fim do texto do TP, estão grafadas as palavras reliqua desiderantur, frequentemente traduzidas pela expressão "falta o resto".

5. Conferir Auctoris epistola ad amicum (GIII, 272) ou, na tradução de José Perez (Spinoza, s/d, p. 29), Carta de Spinoza a um amigo sobre o Tratado político. Em nota preliminar à leitura desta obra nas $O P$, os editores reproduzem essa carta de Espinosa, em que este afirma estar às voltas com a produção de um tratado de conteúdo político, concedendo - inclusive - alguns detalhes de sua composição. A carta menciona apenas o escopo dos seis primeiros capítulos.

6. "Império" sempre ocorre neste artigo traduzindo o termo imperium, diversas vezes empregado por Espinosa. Esse vocábulo aparece, na obra do filósofo, em contextos diversos. Ele é usado tanto para designar "forma de governo" (como na expressão "império democrático"), quanto para se referir ao "domínio da própria razão" (como na expressão "viver sob o próprio império da razão") (cf. SO2, p. 269. Ética IV, Apêndice, Capítulo 9). 
em uma República livre, as ciências e as artes são cultivadas, então, da melhor forma, concedendo-se a cada um permissão para ensinar publicamente às suas custas e com o perigo de sua reputação. Reservo, porém, estas questôes e outras semelhantes para outro lugar, pois aqui desejei tratar apenas do que pertence exclusivamente ao império aristocrático. (TP, Capítulo $8, \$ 49$. SO3, p. 345$)^{7}$.

Segundo Espinosa, as academias fundadas com o custeio da república são formadas mais para entravar o espírito do que para efetivamente cultivá-lo; a condição para que as ciências e as artes sejam cultivadas da melhor forma em uma república livre é conceder a qualquer um a licença para ensinar publicamente, por sua própria custa e com o perigo de sua reputação. Todavia, questôes dessa natureza são reservadas pelo autor para um outro lugar e, em função de sua morte, não foram por ele trabalhadas. Espinosa justifica sua decisão de limitar-se a essas poucas palavras sobre o assunto, por ter pretendido - nesse oitavo capítulo - tratar unicamente daquilo que diz respeito somente ao império aristocrático.

Esse fragmento mereceu alguma atenção por parte dos comentadores da filosofia de Espinosa. Raramente, porém, estes se detiveram a observar seu conteúdo de maneira mais profunda.

Entre os mais importantes comentários a esse trecho, está, sem dúvida, o de Luís Machado de Abreu (1993, p. 107-111), em Spinoza - a utopia da razão. Ao abordar o problema da liberdade de pensamento, ele afirma que as instituições estatais são apresentadas por Espinosa como instrumentos de controle e de dominação. "O pecado original - ele afirma - reside na subordinação ao poder que delas dispóe através de mecanismos de financiamento (p. 108)". A proposta espinosana para o ensino estaria, nesse sentido, baseada na iniciativa privada com sanção do império e no jogo da opinião pública. $\mathrm{O}$ modo pelo qual essa iniciativa privada se realizaria, embora não tenha sido expresso por Espinosa, estaria talvez concebido em um ensino centrado no professor. Abreu

7. Nota sobre a tradução: no original, encontra-se Academiae, quae sumptibus Reipublicae fundantur, non tam ad ingenia colenda, quam ad eadem coercenda instituuntur. Sed in libera Republica tum scientiae et artes optime excolentur, si unicuique veniam petenti concedatur publice docere, idque suis sumptibus, suaeque famae periculo. Sed haec et similia ad alium locum reservo. Nam hic de iis solummodo agere constitueram, quae ad solum imperium aristocraticum pertinent. Das traduções mais disponíveis ao público brasileiro, precisamente as de Jose Perez, da Ediouro (Coleção Clássicos de Bolso, s/d), Manuel de Castro, da Editora Abril (Coleção Os Pensadores, 1973 e edições seguintes $[1979,1983 . .]$.$) e de Norberto de Paula Lima, da Editora Ícone (Coleção$ Fundamentos de Direito, 1994), apenas a primeira, de Jose Perez, lembra-se de traduzir o advérbio publice (publicamente), que se refere ao verbo docere (ensinar). 
faz referência também, nesse mesmo sentido, à recusa de Espinosa à cátedra de filosofia que lhe fora oferecida em Heidelberg8.

Antonio Negri (1993, p. 33), por sua vez, a fim de mostrar como a vida cultural e intelectual holandesa era mais intensa fora das academias do que dentro delas, menciona a opinião de Espinosa sobre tais academias no parágrafo 49 do Capítulo 8 do TP. Para o pensador italiano, a crítica espinosana às universidades e sua recusa à cátedra em Heidelberg traduziriam bem essa realidade.

Adolfo Ravà (1933, p. 200), em seu texto "La pedagogia di Spinoza", faz sua referência ao parágrafo 49, ao afirmar que Espinosa desaprovava o modelo de manutenção de universidades através do estado, tendo como sonho a implantação de uma espécie de generale libera docenza.

Esses estudos constituem, em certa medida, o ponto de partida para um aprofundamento na interpretação desse fragmento, que contribui fortemente para um desenvolvimento maior de questōes políticas relativas à educação.

\section{Interpretação}

Espinosa inicia o parágrafo em questão, no texto latino, com a palavra "academiae", que pode receber tanto a tradução "academias", quanto "universidades". Não obstante, não se trata das academias de modo geral, mas das "academias fundadas às custas da República”. A fim de entender a maneira pela qual se constituem tais academias mencionadas por Espinosa, é preciso inicialmente compreender algo a respeito da história da educação pública.

Embora reconheça a existência de formas de educação organizada antes do século XVI, Lorenzo Luzuriaga (1959), em sua História da educação pública, afirma que só a partir da modernidade se encontra "uma intervenção sistemática e continuada das autoridades públicas na educação". Para ele, deve-se definir a "educação pública" como aquela que é criada e gerida pelas autoridades oficiais.

A educação pública, resumidamente, teria vivido, segundo Luzuriaga (1959, p. 1-2), quatro momentos históricos fundamentais, quais sejam: (1) a "educação pública religiosa”, que surgiu no século XVI e perdurou até o século XVIII, correspondendo a um resultado das transformações pelas quais a educação medieval passou sob o impacto da Reforma, determinando que seus adeptos recorressem a autoridades oficiais e dessem sustentação para suas crenças; seu

8. A esse respeito, conferir "Carta 48" da Correspondência de Espinosa (SO4, p. 235-236). Ademais, sugere-se a leitura do artigo "Por que Espinosa recusou o convite para ser professor de Filosofia em Heidelberg?" (Oliveira, 2008). 
objetivo era a formação do fiel; (2) a "educação pública estatal", que emergiu no século XVIII, consistindo em um fruto da secularização do Estado, quando este passou a organizar a educação para seus fins próprios e tinha como objetivo a formação do súdito; (3) a "educação pública nacional", que apareceu após a Revolução Francesa e desenvolveu-se durante o século XIX, configurando um produto da transformação da educação pública estatal; seu objetivo era a formação do cidadão; e, finalmente, (4) a "educação pública democrática", que se mostrou no século XX como uma consequência do aumento da participação do povo no governo nacional e pretendia formar o homem completo?.

Aceitando a classificação apresentada por Luzuriaga, Espinosa - que viveu em meados do século XVII - conheceu apenas a primeira forma de educação pública, a saber, a religiosa. Efetivamente, não é por ser religiosa que este tipo de instituição deixa de ser "fundada às custas da República". Desde o primeiro momento de sua concepção na mente de seu criador - Martinho Lutero -, a educação pública religiosa foi lançada para a responsabilidade de provimento estatal $^{10}$.

Todavia, é preciso ter em mente em qual nível de desenvolvimento estava a educação religiosa na época de Espinosa. Conforme afirma Luzuriaga, é possível dividir esse tipo de educação em dois momentos: no século XVI (quando o sentido religioso do ensino é predominante) e no século XVII, período em que se inicia um novo movimento pedagógico, principalmente com Comenius e Ratke que, embora fossem inspirados em princípios religiosos, tornaram-se, para o historiador da educação italiano, o início da emancipação da educaçãa ${ }^{11}$.

Sabe-se, através de uma nota do tradutor Manuel de Castro (Espinosa, 1979 , p. 326, nota $\left.n^{\circ} 19\right)$, que o pensador holandês, ao mencionar as universidades, tinha em mente o "exemplo que dava a de Leyden, onde o ensino filosófico e teológico tinha principalmente como finalidade estabelecer solida-

9. $\bigcirc$ homem completo é, segundo Luzuriaga, aquele que desenvolve ao máximo suas potencialidades, independentemente de sua classe social e econômica. "Seu caráter é fundamentalmente humanizador". A educação pública democrática, que forma o homem completo, proporciona "o maior grau possível de cultura ao maior número possível de homens." (1959, p. 2).

10. Não é sem razão que Lutero, ao desejar implementar pela primeira vez esse modelo de instrução, escreve - em 1524 - uma carta "aos regedores de todas as cidades da nação alemã para que estabeleçam e mantenham escolas cristãs". Nota-se o caráter de provimento (custeamento) que estaria a cargo do Estado (Luzuriaga, 1959, p. 6-7).

I I. De acordo com Luzuriaga, os caracteres gerais da educação no século XVII são os seguintes: (a) "acentuação do aspecto religioso, dogmático, na educação"; (b) "um desenvolvimento maior da educação pública nos Estados protestantes", (c) "introdução paulatina de idéias científicas e filosóficas na educação" e (d) "começos de uma doutrina pedagógica, especialmente no campo da didática." (1959, p. 12). 
mente no espírito dos estudantes os dogmas da igreja calvinista". Sendo assim, conclui-se, pela mera observação da nota do tradutor, que tal universidade corresponde, de maneira precisa, ao tipo de instituição que Luzuriaga definiu como "educação pública religiosa", que pretende, acima de tudo, formar o fiel.

A seguir, Espinosa dedica-se a apresentar a finalidade da instituição dessas academias que a República custeia. Elas seriam instituídas ${ }^{12}$ - no dizer de Espinosa - menos para cultivar os espíritos (ad ingenia colenda), do que para os entravar (ad eadem corcenda). Os verbos opostos nessa sentença são, como se acha manifesto, colere (cultivar) e coercere (entravar).

O primeiro, em seu sentido primário, significa cultivar [a terra], isto é, preparar [o solo para o plantio]; ligado ao objeto "os espíritos", ganha, porém, o sentido de cuidar, tratar, preparar as inteligências. O verbo colere é diversas vezes empregado por Espinosa em suas obras. Na Ética, entretanto, ele aparece apenas duas vezes, ambas no "Apêndice" da Parte I ${ }^{13}$. Todavia, um fragmento do vigésimo capítulo TTP lança mão do verbo colere em sentido muito similar ao que aparece no parágrafo em questão do TP. Eis o fragmento: "esta liberdade (de pensamento) é absolutamente necessária para o progresso das ciências e das artes, que só podem ser cultivadas (coluntur) por aqueles que têm o pensamento livre e minimamente comprometido." (SO3, p. 243) ${ }^{14}$.

Como se vê, a incidência de colere na obra de Espinosa, pelo menos no que tange a essa temática das ciências e das artes, carrega o sentido de desenvolvimento do espírito e opõe-se radicalmente a coercere (entravar). Conquanto este último verbo figure também em outras obras de Espinosa, como no próprio TTP15,

12. Seria relevante acrescentar algo sobre o verbo instituere e sua incidência na obra de Espinosa. Todavia, ele aparece aqui querendo significar meramente a criação, a formação e, talvez — em uma leitura mais livre - a constituição e a manutenção das academias por parte da república. Isso, para objetivar mais este texto, parece já o suficiente.

13. No "Apêndice" da Parte I lê-se, em primeiro lugar (SO2, p. 78): "[...] dicunt enim Deum omnia propter hominem fecisse, hominem autem ut ipsum coleret" [...] porque dizem que Deus fez todas as coisas em função do homem e o homem, em contrapartida, para que lhe cultuasse]; e, em segundo lugar (SO2, p. 79): "[...] unde factum ut unusquisque diversos Deum colendi modos ex suo ingenio excogitaverit ut Deus eos supra reliquos diligeret et totam naturam in usum cæcæ illorum cupiditatis et insatiabilis avaritiæ dirigeret" [...] daí o fato de cada um ter pensado diversos modos de cultuar Deus, de acordo com seu próprio espírito, para que Deus os estimasse mais do que o restante e dirigisse toda a natureza em proveito dos seus cegos desejos e da sua insaciável avareza]. O substantivo cultus também aparece duas vezes nesse "Apêndice".

14. No original: "[...] haec libertas apprime necessaria est ad scientias, \& artes promovendum; nam hae ab iis tantum foelici cum successu coluntur, qui judicium liberum, \& minime praeoccupatum habent".

15. Um exemplo de incidência de coercere no TTP (também no vigésimo capítulo, SO3, p. 244) é o seguinte: "Cum itaque humanam naturam sic comparatam esse constet, sequitur, leges, quae de opinionibus conduntur, non scelestus, sed ingênuos respicere, nec ad malignos coercendendum, sed potius ad honestus irritandum condi, nec fine magno imperii periculo defendi posse" [Portanto, sendo evidente que a natureza humana é assim constituída, segue-se que as leis que dizem respeito às

Pro-Posições, Campinas, v. 21, n. 1 (61), p. 197-212, jan./abr. 2010 
ele será aqui investigado segundo a significação que ganha na parte III da Ética ${ }^{16}$. O sentido que coercere ganha nessa parte determina, de certo modo, o sentido que ele receberá nas demais incidências.

Como se sabe, a terceira parte da Ética é destinada a tratar da teoria dos afetos, e é, pois, justamente na definição de afeto que o verbo coercere aparece nesse domínio pela primeira vez. Afirma Espinosa:

Por afetos entendo as afecçóes do corpo, pelas quais a potência de agir desse mesmo corpo é aumentada ou diminuída, favorecida ou entravada (juvatur vel coercetur), assim como as idéias destas afecçôes. Se, portanto, podemos ser causa adequada de uma destas afecções, por afecção entendo uma ação, nos outros casos, entendo uma paixão. (EIII, Def. 3. SO2, p. 138).

De acordo com o que se lê, "entravar" é tomado por Espinosa como um resultado de uma afecção do corpo oposta àquela que gera o aumento da potência de agir desse corpo. Portanto, segundo o sentido que a parte III da Ética aplica ao verbo coercere (e, segundo se pode deduzir, é o sentido que esse termo ganha fundamentalmente nas partes IV e V), conclui-se que ele tem como desígnio referir-se ao processo de "diminuição da potência".

À luz desse esclarecimento, é lícito retomar a passagem do parágrafo do TP aqui visado com novo olhar. As academias custeadas pela república seriam, pois, instituídas com a finalidade de diminuir a potência dos espíritos e não de aumentá-la. Seria, portanto, um ensino que engendra o conhecimento inadequado.

Na sequência, Espinosa afirma que, em uma "república livre", ao contrário do que se passa nas repúblicas que até então se apresentavam ao conhecimento de Espinosa, a melhor forma de serem cultivadas as ciências e as artes estaria em conceder a cada um a licença ou a permissão para ensinar publicamente através de seu próprio financiamento e sob o perigo de sua reputação.

É preciso, inicialmente, entender o que seria, em sentido espinosano, uma "república livre". Naturalmente, o tratamento dessa questão, posta assim dessa maneira, exigiria um esforço que excederia muito os limites deste texto. Como,

opiniões contemplam não os criminosos, mas os espíritos livres; são feitas não para entravar os maus, mas para irritar os honestos; além disso, não podem manter-se sem grande perigo para o império].

16. Várias vezes Espinosa emprega coercere na Ética, nenhuma delas na parte I. Na parte II há apenas uma menção, na definição que se segue ao axioma II, qual seja: "Cum corpora aliquot ejusdem aut diversæ magnitudinis a reliquis ita coercentur ut invicem incumbant..." (SO2, p. 99100). [Quando uma certa quantia de corpos da mesma ou de diversas grandezas é entravada pela ação dos outros corpos a aplicar-se uns sobre os outros.... . A maior parte das incidências de coercere na Ética está na terceira, quarta e quinta partes. 
porém, esse trecho pretende caracterizar simplesmente o ensino em uma "república livre", é possível recortar a consideração do que seja uma tal "república livre" nos contornos do Capítulo 20 do TTP, que traz por título "Onde se mostra que em uma República Livre é lícito a cada um pensar o que quiser e dizer aquilo que pensa." (SO3, p. 239) ${ }^{17}$.

Nesse capítulo, o filósofo holandês demonstra que, da mesma forma que é impossível retirar aos indivíduos sua liberdade de pensar e de dizer o que pensam, também não é conveniente entregar-lhes uma liberdade irrestrita. Então, passa a explicar o que se segue dos fundamentos da república. Para Espinosa, o fim da república não é subjugar os homens pelo medo e submetê-los a um direito de outrem, mas livrar o indivíduo do temor, fazendo que ele viva em segurança; em outros termos, isso significa fazer com que se conserve da melhor maneira o seu direito natural, isto é, sua capacidade de perseverar na existência. Mais especificamente, Espinosa afirma que a república se destina a fazer com que o corpo e a mente dos homens exerçam suas funçôes em segurança, arrematando: "o verdadeiro fim da República é, pois, a liberdade" (SO3, p. $241)^{18}$. Se for assim, a Libera Republica será aquela em que a república atinge propriamente o seu verdadeiro fim.

Nessa república livre - essa é a argumentação espinosana - a melhor maneira de cultivarem-se (excolere) ${ }^{19}$ as ciências e as artes é conceder a cada um permissão para ensinar. Nesse sentido, cabe analisar precisamente o verbo "conceder" (concedere) e observar que seria a república a responsável por conceder permissão para o ensino. Ela teria, pois, o poder de sancionar o ensino, mas deveria concedê-lo não a alguns, mas "a cada um", sem qualquer restrição. Em outros termos, não haveria quaisquer requisitos obrigatórios para o agente do ensino, todos teriam o direito de ensinar, e não somente de ensinar, mas de "ensinar publicamente" (publice docere).

Para entender este advérbio, publice, que se liga a docere, interessa ler o que se segue: ensinar publicamente "às suas custas e sob o perigo da sua reputação".

17. No original: "Ostenditur, in Libera Republica unicuique et sentire, quae velit, et quae sentiat, dicere licere".

18. No original: "Finis ergo Reipublicae revera libertas est".

19. Optou-se por manter a tradução "cultivar", não só para colere, como também para excolere, tendo em vista que o acréscimo do prefixo ex- não altera significativamente o conteúdo do verbo. Outra saída seria utilizar "desenvolver", "promover" ou outro verbo semelhante. Se há sempre uma razão para um filósofo empregar dois termos diferentes - como magistralmente lembra Deleuze em uma de suas aulas sobre Espinosa, remetendo-se à necessidade de distinguir com palavras diferentes affectus e affectio - também parece ter havido, neste caso, razão para Espinosa empregar verbos semelhantes: colere (a opor-se a coercere) e, depois, excolere (para referir-se ao desenvolvimento do ensino em uma Libera Republica). 
A primeira expressão ("às suas custas") permite deduzir, portanto, que a atuação da república - no que tange ao ensino - estaria limitada à emissão de concessão para ensinar; dessa forma, ela estaria descomprometida de qualquer financiamento para a educação, pois este ficaria a cargo de cada um, isto é, de cada um dos que se dispusessem a ensinar.

A segunda expressão ("sob o perigo de sua reputação") apresenta, fundamentalmente, dois aspectos: (1) a ameaça (periculo) de, uma vez ofertando mau ensino, o professor cair em descrédito por parte do alunado, deixando por conseguinte - de ter público e não conseguir sustentar seu trabalho e (2) a ameaça (periculo) de, uma vez infringindo as leis da república, sofrer as represálias previstas na legislação.

O primeiro aspecto, a reputação pela qualidade do ensino, o próprio Espinosa a sentiu ao dar lições sobre os Princípios da Filosofia de Descartes a Caseario, um jovem que lhe havia procurado com esse desígnio ${ }^{20}$. A partir das lições dadas a esse rapaz, Espinosa ganhou fama de profundo conhecedor do cartesianismo, atraindo para si a atenção dos homens interessados em receber instrução nessa matéria.

Vê-se, nesse exemplo tomado da vida do próprio Espinosa, como se constitui a reputação pela qualidade: ela promove o nome do professor em caso de bom ensino, ou o arruína, em caso de ter administrado um ensino ruim.

Para compreender melhor o segundo aspecto, qual seja, a reputação ante as prerrogativas da lei, cabe adentrar as linhas do já mencionado derradeiro capítulo do TTP. Este, efetivamente, aponta - de início - que o império violento é aquele que exerce poder sobre o foro íntimo de seus cidadãos, prescrevendolhes de antemão o que devem admitir como verdadeiro e falso. Como, segundo Espinosa, isso é impossível ${ }^{21}$, é mister reconhecer a cada um sua liberdade de pensar e de dizer o que pensa.

Não obstante, segundo o TTP, não se deve conceder ao homem uma liberdade sem restrições, pois como se pode cometer crimes por ações, pode-se também cometê-los por palavras. Então, Espinosa passa a discorrer sobre quais seriam essas restriçốes.

20. Conferir cartas 8 e 9 da Correspondência de Espinosa (SO4, p. I38- | 45).

21. Tal cerceamento seria impossível por várias razões, enunciadas por Espinosa nas mais diversas formas: ( I ) pois mandar nos ânimos dos homens não é tão fácil quanto mandar nas línguas; (2) pois cada qual tem o seu juízo singular sobre as coisas e as cabeças variam tanto quanto os paladares, e também (3) pois os juízos dos homens dependem da maneira que cada um é e da afecção pela qual cada um está tomado. Todavia, o que importa, sobretudo, é que, para formar o império, os homens renunciaram somente ao direito de agir sob sua própria deliberação, e não ao direito de pensar e de dizer o que pensam. Essa ideia apresenta um rompimento significativo entre o pensamento político de Espinosa e Hobbes (cf. Espinosa, 1988, p. 424, nota 2, de Diogo Pires Aurélio). 
Segundo Espinosa, o sujeito apenas renuncia a agir segundo seu próprio arbítrio, mas pode pensar e dizer o que pensa, desde que se limite a dizer e ensinar, sustentando suas conclusões "só pela razão, sem fraudes, cólera, ódio, nem intenção de introduzir pela autoridade de seu decreto outro ânimo na República." (SO3, p. 241. TTP, Capítulo 20) ${ }^{22}$.

A expressão sola ratione (só pela razão) configura um caso de ablativo de instrumento (ablativus instrumentis) que visa designar, em linguagem espinosana, "segundo os ditames da razão" ou "sob o império da razão", ou ainda - e talvez este seja o modo de conceber mais apropriado - "pela condução da razão".

Ex ratione ductu (pela condução da razão) opõe-se a ex affectu ductu (pela condução da paixão), o que justifica o non autem na última citação de Espinosa, depois do qual o filósofo passa a listar uma série de afetos contrários à razão. Destes, o primeiro que Espinosa menciona é a "fraude" (dolus). Dolus, entretanto, não aparece como definição nas "Definições dos Afetos" que encerram a parte III da Ética. Ele aparece, por sua vez, na proposição 72 da parte IV, onde se lê: "O homem livre nunca age com fraude, mas sempre com fidelidade." (SO2, p. 264) 23 .

É interessante, para o escopo deste trabalho, adentrar um tanto na demonstração dessa proposição. Espinosa raciocina da seguinte forma: fazendo algo com fraude, enquanto seja livre, o homem o faria de acordo com os ditames da razão, pois - segundo lembra - só assim ele é dito livre; consequentemente, a fraude (dolus) seria uma virtude e, então, seria mais conveniente a ele agir fraudulentamente para conservar o seu ser. Para Espinosa, isso é o mesmo que dizer que seria conveniente aos homens estarem em acordo uns com os outros apenas por palavras, sendo, no entanto, uns contrários aos outros, o que resulta absurdo.

Todavia, resta ainda - da última citação do TTP feita - analisar o que seria a "intenção de introduzir pela autoridade de seu decreto outro ânimo na República".

Para tanto, parece necessário recorrer à proposição 68 da mesma parte IV da Ética, que afirma: "O homem que é conduzido pela razão é mais livre na cidade (onde vive de acordo com as leis comuns) do que na solidão, onde obedece apenas a si mesmo". A demonstração é a seguinte: enquanto um homem é conduzido pela razão, ele não obedece por medo; ao contrário, esforçando-se

22. No original: sola ratione, non autem dolo, ira, odio,nec animo aliquid in recpublicam ex authoritate sui decreti introducendi, defendat.

23. No original: Homo liber nunquam dolo malo sed semper cum fide agit. Optou-se aqui por traduzir fides por "fidelidade", e não "boa fé", por entender-se que fides adquire, neste momento da Ética, aquilo que, no TTP, Espinosa opôs à bajulação, à desonestidade, ou então, a "dizer uma coisa, pensando outra". Não obstante, há outras passagens na obra espinosana em que, reconhecidamente, fides reclama a tradução "fé" ou mesmo "boa fé". 
por conservar o seu ser segundo os ditames da razão, esforçar-se-á simultaneamente para ter uma vida livre, desejando a vida em comum e a utilidade comum; consequentemente, desejará viver de acordo com as leis da cidade. Portanto, Espinosa conclui que o homem conduzido pela razão deseja conservar os direitos comuns da cidade (communia civitatis jura tenere).

Vê-se, pois, que o discurso apresentado por Espinosa, no encerramento da exposição geométrica da parte IV da Ética, está em íntima associação com o trecho do TTP aqui tomado a exame, sobretudo quando o filósofo evidencia, por um exemplo, o que entende por "demonstrar ideias" pela razão, sem a "intenção de introduzir pela autoridade de seu decreto outro ânimo na República." (SO3, p. 241. TTP, Capítulo 20).

O exemplo é o seguinte: um homem demonstra ser uma lei contrária à razão e, por isso, acredita que ela deva ser revogada; se submeter sua opinião ao julgamento dos poderes soberanos, principalmente dos legisladores, sem ousar intentar qualquer ação contrária àquilo que a dita lei prescreve, ele será tido com o mesmo valor de um cidadão exemplar; se, em contrapartida, alguém se valer disso para acusar de iniquidade o magistrado, tornando-o odioso ao vulgo, ou passar a operar subversivamente com a finalidade de revogar a lei, precisamente a despeito desse magistrado, então será perturbador e rebelde.

Segundo o que se pode depreender da leitura das últimas proposições da parte IV da Ética, o sujeito do primeiro caso seria um homem livre e o do segundo, um servo ${ }^{24}$; o primeiro estaria sob a conduta da razão e o segundo, sob condução da paixão (ex affectu ductu). $\mathrm{O}$ primeiro agiria com fidelidade (fides) para com a república; o segundo, por sua vez, estaria sendo infiel à república e atentando contra ela, simplesmente em conformidade com seu próprio decreto, e não mediante o que a maioria fixou. Por isso, Espinosa ressalta mais adiante em seu TTP que as opiniōes subversivas são aquelas que determinam o imediato rompimento do pacto pelo qual cada um renunciou ao direito de agir por seu livre entendimento.

Ainda no vigésimo capítulo do TTP, Espinosa afirma - em outro momento - que, no caso dessa liberdade (de pensar, filosofar e ensinar) deixar de ser concedida aos cidadãos, haverá dois tipos de homens: ou aqueles que pensam uma coisa e dizem outra (os bajuladores), que causam - segundo Espinosa - a corrupção da fidelidade à república, além de instigar a adulação e a perfídia; ou aqueles que não abrem mão de seu juízo e resistem (os homens livres) que - no dizer do filósofo - fizeram-se ainda mais livres por terem obtido uma boa educação, possuírem íntegros costumes e virtude (TTP, Capítulo 20. SO3, p. 244).

24. Parece conveniente lembrar aqui a oposição que Espinosa oferece entre o homem livre e o servo, no escólio da proposição 63 da parte IV da Ética. 
Nesse sentido, fidelidade e bajulação opõem-se. Uma república que não conceda a liberdade de pensar e dizer o que se pensa terá em melhor conta os bajuladores do que aqueles que lhe são fiéis.

Retomando o parágrafo 49 do Capítulo 8 do TP, pode-se agora compreender o exato sentido da sentença "sob o perigo de sua reputação" e constatar que a república livre não se limitaria a conceder a permissão ao ensino, mas cumpriria também, de alguma forma, a função de acompanhar o ensino oferecido a cada um, a fim de garantir a prevalência da lei decidida pela maioria ${ }^{25}$.

Parece mais viável agora compreender também o sentido do publicamente que caracteriza o ensinar. $\mathrm{O}$ ensino é público não só por ter obtido concessão da república, mas por estar compreendido dentro das suas leis e ser limitado por elas. Assim, sem provocar alteraçōes na república, o ensino conservará a república livre, de modo a garantir que outros também possam pensar, dizer e ensinar publicamente as suas ideias.

Todavia, Espinosa limita-se a mencionar essas ideias, reservando para outro lugar (ad alium locum) o aprofundamento dessas questóes e de outras semelhantes. É possível que nesse outro lugar fossem especificados os meios pelos quais a república concederia a liberdade de ensinar a cada um.

Mas qual seria, enfim, o lugar do TP em que estariam sendo desenvolvidas as questōes semelhantes a essa sobre o ensino em uma república livre?

O TTP talvez ofereça uma pista ao afirmar que conceder liberdade de pensar e dizer o que se pensa é a melhor forma de governar e a que, ao mesmo tempo, acarreta os menores incômodos. Essa forma de governo seria, segundo o autor, a democracia (que mais se aproxima do estado de natureza), em que todos decidem fazer valer a opinião que tenha o voto da maioria (SO3, p.245. TTP, Capítulo 20).

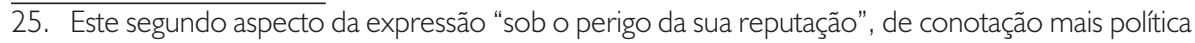
em comparação com o primeiro, pode ser observado na correspondência que Espinosa - alguns anos antes da redação do TP - enviou a Velthuysen. Essa epístola também contém a expressão famae periculo, aqui discutida. Nela, o filósofo holandês ressaltou não ter tido a intenção de publicar, sem permissão, um escrito de seu interlocutor (cf. Carta n ${ }^{\circ} 42$ ), que se contrapunha ao seu TTP: "E embora eu acredite que isso [divulgar o teu escrito] possa fazer-se sem nenhum perigo de tua reputação, contanto que teu nome não seja inscrito nele, nada farei, a menos que me concedas licença para divulgá-lo (Carta n 69. SO4, p. 300)". No original: "Et quamvis credam, posse id fieri, absque ullo tuae famae periculo, si modo nomen tuum eidem non inscribatur, nihil tamen faciam, nisi mihi ejusdem evulgandi licentiam concedas". Nessa passagem, vê-se que, para Espinosa, a reputação do autor ficaria a salvo se este suprimisse o próprio nome ao publicar seu escrito; esta foi, como se sabe, uma prática muito comum entre aqueles que então pretendiam permanecer sem problemas com as autoridades políticas e religiosas. Isso evidencia outra vez a esfera política da expressão famae periculo. 
Portanto, ao afirmar que em uma república livre a melhor forma de serem cultivadas as artes e as ciências seria conceder a cada um o direito de ensinar por suas próprias custas e sob o perigo de sua reputação, Espinosa está se referindo a algo que se efetiva no regime democrático.

\section{Conclusão}

Retomando a concepção e a periodização da educação pública proposta por Lorenzo Luzuriaga (1959), constata-se que Espinosa presenciou a fase originária e primitiva dessa forma de desenvolvimento do ensino, que praticamente inexistiu antes da Idade Moderna. Através do exemplo que lhe dava a Universidade de Leyden, o filósofo holandês travou conhecimento com a educação pública religiosa e dispensou-lhe as críticas apontadas nesse trabalho.

Espinosa, embora tenha vivido no século XVII, defendeu ardentemente a liberdade de ensino e deixou manifesto que seu pleno desenvolvimento apenas se efetivaria em um império democrático, onde fosse dada - a cada um - a liberdade de pensar e dizer o que pensa. $\mathrm{O}$ autor do Tratado político estaria, dessa forma, fazendo o elogio de uma educação pública baseada na iniciativa de qualquer cidadão que, tendo fidelidade em relação ao império e, daí, em relação àquilo que foi definido pela maioria, se dispusesse a ensinar sem fraudes, só pela condução da razão.

É possível perguntar se esta seria, segundo Luzuriaga, precisamente a forma de educação pública que passou a ser reivindicada no século XX, e que ele chamou de educação pública democrática. Tendo em vista que esta teria como objetivo a formação do homem completo, a resposta parece ser negativa: o ensino livre, que compõe a estrutura da república livre descrita por Espinosa, tem em vista justamente a formação do homem livre. Esse "homem completo" a que se refere Luzuriaga não existe na filosofia espinosana, na medida em que, nessa doutrina, o homem define-se como parte da natureza, e esta condição não parecerá jamais conciliável com a expressão "homem completo".

De maneira ainda mais precisa, cabe ressaltar que o modelo de educação proposto por Espinosa (aquele em que a república concede a cada qual a liberdade de ensinar) é precisamente oposto ao modelo da educação pública religiosa. Este último é caracterizado pelo filósofo como entrave aos espíritos, enquanto a educação na Libera Republica, como foi visto, promove a liberdade.

Nesse sentido, convém recordar que Espinosa, no parágrafo 7 do segundo capítulo do TP, afirma que "tudo o que acusa o homem de impotência, não pode se referir a sua liberdade (SO3, p. 279) ${ }^{26 "}$; o homem define-se, no pen-

26 No original: quicquid [igitur] hominem impotentiae arguit, id ad ipsius libertatem referri nequit. 
samento espinosano, como livre à medida que, entre outras coisas, pode usar sua razão com liberdade.

Desse modo, o que se encontra no pensamento de Espinosa em relação à constituição da educação em uma república livre é a defesa plena da liberdade política; o Capítulo 20 do TTP revela com precisão quais ideias seriam consideradas subversivas naqueles que pretendem promover o ensino no império democrático, revelando que a liberdade ali concedida não permitiria à iniciativa particular de qualquer cidadão ensinar o que fosse contrário ou ameaçasse a paz da cidade.

A partir da análise desse parágrafo, é possível encontrar ainda novos esclarecimentos sobre a recusa de Espinosa à cátedra de filosofia em Heidelberg ("Carta 48”. SO4, pp. 235-236). Naquela oportunidade, o pensador holandês afirmou que sua resposta negativa ao convite tinha como razões, em primeiro lugar, o fato de que instruir publicamente a juventude obstaria seus avanços na filosofia e, em segundo lugar, o fato de não saber quais seriam os limites da liberdade de ensinar (libertas Philosophandi) que lhe fora prometida. Como se nota também nesse caso, a liberdade de ensino aparece desempenhando um papel fundamental.

Para o filósofo, o verdadeiro ensino só se efetiva se for engendrado com liberdade em um império democrático e livre; do contrário, a educação entrava as inteligências e, ao invés de propiciar a liberdade, beneficia os bajuladores e dá espaço para que a infidelidade de alguns homens prejudique a segurança e a paz de todo império.

Referências bibliográficas

ABREU, L. M. Spinoza: a utopia da razão. Lisboa: Vega, 1993.

ESPINOSA, B. Ospensadores. São Paulo: Abril Cultural, 1979.

ESPINOSA, B. Tratado teológico-politico. Notas, tradução e introdução de D. P. Aurélio. Lisboa: Imprensa Nacional, 1988. (Série Estudos gerais).

LUZURIAGA, L. História da educação pública. Tradução de Luiz Damasco Penna e J. B. Damasco Penna. São Paulo: CIA Editora Nacional, 1959.

NEGRI, A, A anomalia selvagem. Tradução de Raquel Ramalhete. Rio de Janeiro: Editora 34, 1993. (Coleção Trans).

OLIVEIRA, Fernando Bonadia de. Por que Espinosa recusou o convite para ser professor de Filosofia em Heidelberg?". Trilhas filosóficas, Caicó-RN, n. 1, p. 101-112, jan./jun. 2008.

RAVÀ, A. La pedagogia di Spinoza. In: Septimana spinozana. Hagae Comitis: M. Nijhoff, 1933, p. 195-207. (Volume comemorativo dos 300 anos de nascimento de Espinosa).

SPINOZA, Opera. Im Augrag der Heidelberger Akademie der Wissenschaften herausgegeben von Carl Gebhardt. Heidelberg, C. Winter, 1925, 2: Auflage 1972. 4 v. 
SPINOZA, B. Tratado político. Tradução e prefácio de José Perez. Rio de Janeiro: Ediouro; Tecnoprint, s.d.

SPINOZA, B. Tratado político. Tradução de Norberto de Paula Lima. São Paulo: Ícone, 1994.

Recebido em 16 de abril de 2009 e aprovado em 18 de setembro de 2009. 